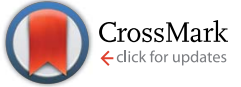

Cite this: RSC Adv., 2017, 7, 2415

Received 26th October 2016 Accepted 5th December 2016

DOI: $10.1039 / c 6 r a 25834 d$

www.rsc.org/advances

\section{A novel 5-FU/rGO/Bce hybrid hydrogel shell on a tumor cell: one-step synthesis and synergistic chemo/photo-thermal/photodynamic effect $\uparrow$}

\author{
Ying Yang, ${ }^{a}$ Lin Zhu, ${ }^{b}$ Feng Xia, ${ }^{a}$ Baoyou Gong, ${ }^{a}$ Anjian Xie, ${ }^{a}$ Shikuo Li, ${ }^{a}$ \\ Fangzhi Huang, ${ }^{a}$ Shaohua Wang, ${ }^{a}$ Yuhua Shen ${ }^{\star a}$ and David T. Weaver ${ }^{\star b}$
}

\begin{abstract}
In this study, a novel drug-loaded inorganic nanoparticle-biomolecule hybrid hydrogel shell containing fluorouracil (5-FU)/reduced graphene oxide ( $\mathrm{rGO}$ )/Brassica chinensis extract (Bce) on tumor cells was firstly constructed through a facile one-step method. The Bce stems from a natural green vegetable for improving the bio-compatibility of $5-\mathrm{FU} / \mathrm{rGO} /$ Bce hydrogel and presents multi-functions in this system. As both a reducing and a cross-linking agent for GO, Bce is beneficial for the fast formation of a rGO/ Bce hybrid hydrogel at body temperature $\left(37^{\circ} \mathrm{C}\right)$ before laser irradiation, as well as being an excellent photo-sensitizer for inducing the generation of cytotoxic singlet oxygen $\left({ }^{1} \mathrm{O}_{2}\right)$ to kill tumor cells by means of laser radiation. The $\mathrm{rGO}$ in the hybrid hydrogel possesses photothermal characteristic for the hyperthermia antitumor. After loading anticancer drugs, the formed 5-FU/rGO/Bce hybrid hydrogel shells encapsulated on the tumor cells in situ exhibit three competitive advantages, i.e., retaining the high concentration of drugs around tumor cells to enhance the localized antitumor effect, reducing the side effects by hindering drugs from migrating to normal tissue, and displaying effectively synergetic chemo/photo-thermal/photodynamic therapies. This study provides a new strategy to exploit the multifunctions of hybrid hydrogel materials for effective biomedical applications.
\end{abstract}

\section{Introduction}

The traditional drugs or treatments for cancer are extremely invasive to the human body, such as the large amount of pain of cancer patients through chemotherapy (CT), which could cause multiple complications, including hair loss, anemia and infertility at the same time..$^{1,2}$ Therefore, new therapies that do not affect a wide range of body parts and only the cancer cells must be developed, which would be a significant improvement in the field of cancer research.,

In recent years, some highly effective anti-cancer therapies with few or minimal undesired toxic effects have been studied, such as photo-thermal therapy (PTT) and photodynamic therapy (PDT). PTT ${ }^{5-8}$ with little damage from the near infrared (NIR) laser to the human body and a short treatment time of a matter of minutes could reduce the pain experienced by sufferers. However, PTT could hardly be used alone for cancer treatment due to the limited lethality. On the other hand, PDT ${ }^{9-13}$ exhibits good selectivity and can be repeated, which does not affect the

${ }^{a}$ School of Chemistry and Chemical Engineering, Anhui University, Hefei 230601, P. R. China.E-mail: s_yuhua@163.com

${ }^{b}$ Institute of Health Sciences, Anhui University, Hefei 230601, P. R. China. E-mail: David.weaver.t@gmail.com

$\dagger$ Electronic supplementary information (ESI) available. See DOI: $10.1039 / \mathrm{c} 6 \mathrm{ra} 25834 \mathrm{~d}$ function of the hematopoietic and immune system. Nevertheless, improper selection of the photo-sensitizer can also cause adverse reactions of light allergy, such as a local skin rash or blisters. ${ }^{14-17}$ According to the above proposed obstacles, we aim to construct a suitable hydrogel carrier containing a photo-thermal agent and a photo-sensitizer combined with chemotherapeutic drugs on tumor cells for an effective and localized therapy, which proceeds in the following three main aspects.

Firstly, graphene oxide (GO)-based hydrogel, ${ }^{18,19}$ a kind of new material developed in recent years, has excellent mechanical properties and biocompatibility. The edge of the GO nanosheet is rich in carboxyl, hydroxyl and epoxy groups, which are very easy to directly combine with hydrophilic drugs. At the same time, the $\mathrm{sp}^{2}$ conjugate region of the GO surface layer can also provide a platform for the loading of hydrophobic drugs ${ }^{20,21}$ so the GO-based hydrogel can be used as a commendable drug carrier. In addition, GO and its chemical derivatives possess a certain photo-thermal conversion ability and also can be used in the PTT. ${ }^{22-24}$

Then, the direct synthesis of multi-function biological medicine by using natural products instead of noxious chemicals, is a current research trend in the biological medicine field. For this purpose, our daily vegetables (or their extracts) are a great choice. For example, our group has used pepper extract to prepare Se and $\mathrm{Ag}$ nanoparticles; ${ }^{25}$ some research groups ${ }^{26,27}$ use fresh alfalfa, lemon grass and citronella geranium leaves to synthesize gold 
and silver nanoparticles through a one-step method. Our group has also previously used amaranth extract (ARE) to prepare a GObased hydrogel. ${ }^{28}$ In this work, Brassica chinensis, a traditional green vegetable grown in China and Southeast Asia, has a long history of cultivation and mature cultivation techniques, and is not limited by the seasons compared to ARE, which was chosen as the novel raw material of cross-linking and reducing agent to prepare GO-based hydrogel through a one-step and facile method. In addition, Bce possesses extremely plentiful biomolecules containing chlorophyll, amino acids, sugars, vitamin $\mathrm{C}$ (Vc), folic acid and enzymes, ${ }^{29-31}$ which could transform the GO into reduced graphene oxide (rGO) along with the formation of a rGO/Bce hydrogel network through the main driving forces of redox, hydrogen bonding, $\pi-\pi$ interaction, or electrostatic interaction between GO and Bce. ${ }^{28,32}$ In addition, Bce also can be used as a photo-sensitizer due to the enriched chlorophyll, leaf protein and reduced amino acids encapsulated in the hydrogel, which induced the release of singlet oxygen $\left({ }^{1} \mathrm{O}_{2}\right)$ under laser irradiation for the realization of PDT. This idea and practice has not been reported before.

Finally, recent research shows that a synthetic cell shell ${ }^{33}$ that simulates other biological natural shell-like cocoons, diatoms, egg, etc. ${ }^{34,35}$ has important significance and broad application prospects in the aspect of cell protection, storage, transportation and treatment. Inspired by these, to synthesize a smart drug loaded shell on the surface of the specific cancer cell is a novel idea for the application of tumor therapy with a high efficiency and low toxicity.

In our work, we report a convenient and green route for the three-dimensional self-assembly of GO nanosheets with Bce and 5-FU chosen as a model anticancer drug, and a novel multifunctional 5-FU/rGO/Bce hybrid hydrogel shell formed in situ on the cancer cells. In this hybrid hydrogel shell, the high concentration of drugs could be retained around tumor cells through the fast gelation of $5-\mathrm{FU} / \mathrm{rGO} / \mathrm{Bce}$ at body temperature $\left(37^{\circ} \mathrm{C}\right)$ to enhance the effect of localized antitumor through synergetic chemo/photo-thermal/photodynamic therapy. This study provides a new strategy to exploit multi-functions of hybrid hydrogel materials for effective biomedical applications.

\section{Experimental}

\subsection{Materials and methods}

Fresh Brassica chinensis (Voucher specimen number 01232-012) was purchased from Hefei, Anhui (P. R. China). Graphite flakes and vitamin $\mathrm{C}(\mathrm{Vc})$ were purchased from Aladdin Chemical Reagent Co. (P. R. China). 1,3-Diphenylisobenzofuran (DPBF) was obtained from Acros Organics (Geel, Belgium, NJ). Fluorouracil (5-FU), $n$-dodecyl- $\beta$-D-maltoside ( $\beta$-DM), 2,2,6,6-tetramethylpiperidine (TEMP), trimethylglycine (tricine), 3-(4,5-dimethyl2-thiazolyl)-2-5-diphenyl-2H-tetrazolium bromide (MTT), Hoechst 33342 and propidium iodide (PI) were purchased from Sangon Company Limited (Shanghai, P. R. China). HeLa cells, immortal human cervical cancer cells used in scientific research and derived from Henrietta Lacks, and Chinese hamster ovary (CHO) cells were both obtained from Key Laboratory of Ecological Engineering and Biotechnology, School of Life Science, Anhui
University (Hefei, P. R. China). Concentrated sulfuric acid $\left(\mathrm{H}_{2} \mathrm{SO}_{4}, 96 \%\right)$, hydrochloric acid $(\mathrm{HCl})$, potassium permanganate $\left(\mathrm{KMnO}_{4}\right)$, sodium nitrate $\left(\mathrm{NaNO}_{3}\right)$, hydrogen peroxide $\left(\mathrm{H}_{2} \mathrm{O}_{2}, 30 \%\right)$, etc., were acquired from Chemical Shanghai Reagent Co. (P. R. China). All chemical reagents were of analytical grade and were used without further purification. Deionized (DI) water was gained from a Milli-Q water purification system and used for the experiments.

UV-Vis spectra of samples were obtained on a U-3900 UV spectrophotometer (Hitachi, Japan) in the range of 200$1000 \mathrm{~nm}$. Scanning Electron Microscopy (SEM) images were taken by using an $\mathrm{S} 4800$ scanning electron microscope operated at $5 \mathrm{kV}$. X-ray Diffraction (XRD) patterns were performed on an $\mathrm{XD}$-3 X-ray diffractometer using a $\mathrm{Cu}-\mathrm{K} \alpha$ radiation source $(\lambda=$ $1.5418 \AA$ A). The atomic force microscopy (AFM) images were obtained by using a Veeco Multimode 8 scanning probe microscope in the tapping mode. Fourier transform infrared (FT-IR) spectra were acquired using a NEXUS-870 spectrophotometer (Thermo Fisher, USA, frequency range from 4000 to 500 $\mathrm{cm}^{-1}$ ) with a $\mathrm{KBr}$ pellet. Electron spin resonance spectroscopy (ESR, BRUKER E500) was carried out with microwave frequency of $9.78 \mathrm{GHz}$, modulation frequency of $100 \mathrm{kHz}$, microwave power of $10 \mathrm{~mW}$, modulation amplitude of $1 \mathrm{G}$, time constant of 40 milliseconds, field sweep of $100 \mathrm{G}$ and center field of 3480 mT. Fluorescence images were recorded on a DMI3000B inverted fluorescence microscope (Leica, German). IR thermal imaging was performed with an IR thermal camera (Fluke, Everett, WA). Raman spectra of the samples were obtained using a Jobin Yvon Lab Ram HR 800 equipped with a $532 \mathrm{~nm}$ laser (Renishaw, UK). The OD values of MTT assay were measured by a RT-2100C spectro-photometric micro-plate reader (Rayto, Shenzhen, P. R. China). The chromatograms were obtained by high performance liquid chromatography (HPLC) equipment that consisted of a Waters Delta 600 solvent delivery system, a Waters 717 plus Autosampler, a Waters 2998 Photodiode array detector, a Waters 600 controller and a data acquisition/processing computer with Empower ${ }^{\mathrm{TM}}$ software (Waters, Milford, MA), and the analyses were performed in a SinoChrom ODS-BP 5 PoChrom OD $(4.6 \times 250 \mathrm{~mm})$ at ambient temperature with a mobile phase of phosphoric acid/ methanol $(98: 2, \mathrm{v} / \mathrm{v})$ at a flow rate of $1.0 \mathrm{~mL} \mathrm{~min}^{-1}$. The injection volume was $20 \mu \mathrm{L}$. On-line UV spectra were recorded in the range of 190-600 $\mathrm{nm}$ and the $\lambda 242 \mathrm{~nm}$ trace was used for the calculation of peak areas for all the samples.

\subsection{Preparation of the GO and Bce}

GO was prepared from graphite powder by a modified Hummers method following the literature procedure. ${ }^{36}$ Fresh and green Brassica chinensis was cleaned and soaked in DI water for $1 \mathrm{~h}$, followed by keeping in a cool and dry place, protected from light. Subsequently, the dry and chopped Brassica chinensis was put into a juicer for squeezing juice and then centrifuged at $4500 \mathrm{rpm}$ for $10 \mathrm{~min}$. Finally, the emerald green supernatant as Bce was collected and preserved in the dark for further use. The concentrations of as-prepared GO and Bce were both obtained by a drying and weighing method. 


\subsection{Preparation of the $\mathrm{rGO} /$ Bce hybrid hydrogel}

The optimal conditions for the formation of an ideal $\mathrm{rGO} / \mathrm{Bce}$ hybrid hydrogel were explored. (1) Different concentrations of GO $\left(2,4,6,8 \mathrm{mg} \mathrm{mL}^{-1}\right)$ or Bce $\left(5.7,11,17,34 \mathrm{mg} \mathrm{mL}^{-1}\right)$ for the various gelation time were tested. (2) Different mixed volume ratios of GO to Bce ( $V_{\mathrm{GO}}: V_{\mathrm{Bce}}$ of $0.5: 1,1: 1,1.5: 1$ or $\left.2: 1\right)$ at different temperature $\left(25{ }^{\circ} \mathrm{C}\right.$ or $\left.37^{\circ} \mathrm{C}\right)$ for the various gelation states were investigated.

\subsection{Measurement of ${ }^{1} \mathrm{O}_{2}$ generation and photo-thermal effect}

The generation of ${ }^{1} \mathrm{O}_{2}$ was determined by monitoring the change of the absorption at $410 \mathrm{~nm}$ of DPBF before and after reaction. Briefly, DPBF ( $1 \mathrm{~mL}, 0.196 \mathrm{mg} \mathrm{mL}^{-1}$ ) was mixed with $1 \mathrm{~mL}$ of various samples (GO, Bce or $\mathrm{rGO} / \mathrm{Bce}$ ), and $2 \mathrm{~mL}$ of the mixture was taken out for the measurement of the absorption intensities at $410 \mathrm{~nm}$ with a $650 \mathrm{~nm}$ laser at predefined time points $(0 \mathrm{~s}, 5 \mathrm{~s}$, $10 \mathrm{~s}, 15 \mathrm{~s}$, and $20 \mathrm{~s}$ ) using a UV-3900 spectrophotometer.

In addition, the generation of ${ }^{1} \mathrm{O}_{2}$ could be also tested by an ESR method. $\beta$-DM (5.2 mg), TEMP (249.5 mg) and Bce $(1.5 \mathrm{mg}$ ) were mixed with a tricine- $\mathrm{NaOH}$ buffer solution $(50 \mathrm{~mL}$, $50 \mathrm{mmol} \mathrm{L}^{-1}, \mathrm{pH} 8.0$ ) to the prepare sample. For the specific experimental methods, refer to our previous work. ${ }^{28}$ The corresponding ESR spectra of Bce were recorded after illumination with a $650 \mathrm{~nm}$ red laser for $30 \mathrm{~min}$. The experiments were independently repeated at least three times.

$1 \mathrm{~mL}$ of DI water or $\mathrm{rGO} /$ Bce dispersion was added in a small bottle and then irradiated with an $808 \mathrm{~nm}$ NIR laser at a power density of $1.0 \mathrm{~W} \mathrm{~cm}^{-2}$ at regular time intervals $(1 \mathrm{~min})$. The infrared (IR)-thermal images and photo-thermal heating curves of the above samples were collected by a Fluke Ti32 thermal IR camera for investigating the photo-thermal effect of the rGO/Bce hybrid hydrogel.

\subsection{Loading of 5-FU in $\mathrm{rGO} / \mathrm{Bce}$}

$1 \mathrm{~mL}$ of 5 -FU (1.0, 2.0 or $\left.4.0 \mathrm{mg} \mathrm{mL}^{-1}\right)$ was added into the GO dispersion ( $4 \mathrm{~mL}, 8 \mathrm{mg} \mathrm{mL}{ }^{-1}$ ) with vigorous stirring, followed by the addition of a Bce dispersion $\left(1 \mathrm{~mL}, 34 \mathrm{mg} \mathrm{mL}^{-1}\right)$ to get 5$\mathrm{FU} / \mathrm{rGO} / \mathrm{Bce}$. The centrifugal supernatant liquid was analyzed by UV-Vis spectroscopy after centrifugation at $8000 \mathrm{rpm}$. The amount of the loaded 5FU (loading efficiency, L.E., \%) was obtained by formula (1).

$$
\text { L.E. }(\%)=\frac{\text { amount of loaded } 5 \mathrm{FU}}{\text { original amount of } 5 \mathrm{FU}} \times 100 \%
$$

In addition, the effect of different volume ratios of 5 -FU $\left(2.0 \mathrm{mg} \mathrm{mL}^{-1}\right)$ loaded in GO to Bce $\left(V_{5-\mathrm{FU} / \mathrm{GO}}: V_{\mathrm{Bce}}=0.5: 1,1: 1\right.$, $1.5: 1$, and $2: 1$ ) on the formation of the $5-\mathrm{FU} / \mathrm{rGO} /$ Bce hydrogel at room temperature $\left(25^{\circ} \mathrm{C}\right)$ and body temperature $\left(37^{\circ} \mathrm{C}\right)$ were studied.

\subsection{5 -FU release experiments}

Various amounts of 5-FU with the concentrations of 1.0, 2.0 or $4.0 \mathrm{mg} \mathrm{mL}{ }^{-1}$ released from $5-\mathrm{FU} / \mathrm{rGO} /$ Bce was performed in phosphate buffer ( $\mathrm{pH} 7.4)$ at $37^{\circ} \mathrm{C} .5-\mathrm{FU} / \mathrm{rGO} /$ Bce was transferred into dialysis bags (MWCO $14000 \mathrm{Da}$ ) and then submerged into $10 \mathrm{~mL}$ of phosphate-buffered saline (PBS) at $37^{\circ} \mathrm{C}$ under continuous shaking. The drug released from the dialysis membranes into the PBS solution was collected at different time durations for analysis. The concentration of released $5 \mathrm{FU}$ was measured by UV-Vis absorption spectroscopy. All the release experiments were performed in triplicate. The release percentage (R.P., \%) of 5FU was calculated according to formula (2).

$$
\text { R.P. }(\%)=\frac{\text { amount of } 5 \mathrm{FU} \text { released }}{\text { amount of encapsulated } 5 \mathrm{FU}} \times 100 \%
$$

\subsection{Cell viability assay}

HeLa cells and CHO cells were seeded at a density of $5 \times 10^{3}$ cells per well into 96-well plates and incubated for $24 \mathrm{~h}\left(37^{\circ} \mathrm{C}\right.$, $5 \% \mathrm{CO}_{2}$ ). The various samples ( $\mathrm{rGO} /$ Bce and 5-FU/rGO/Bce) with specific concentrations were added to the plates, and incubated for a further $24 \mathrm{~h}$. Some of the plates were kept in the dark, while others were exposed to laser light. The plates were returned to the incubator for $6 \mathrm{~h}\left(37^{\circ} \mathrm{C}, 5 \% \mathrm{CO}_{2}\right)$, and the cell viability was determined by MTT assay. ${ }^{28,37}$ All the experiments were repeated six times.

\subsection{Fluorescence microscopic images}

Fluorescence microscopic images were used to demonstrate the formation of a hydrogel shell on the surface of HeLa cells and the in vitro antitumor activities of the samples. HeLa cells were seeded at a density of $5 \times 10^{4}$ cells per well in 6-well plates and incubated for $24 \mathrm{~h}\left(37^{\circ} \mathrm{C}, 5 \% \mathrm{CO}_{2}\right)$. After preparation, $3 \mathrm{~mL}$ of fresh DMEM medium containing $0.6 \mathrm{~mL}$ of various samples was added into each well. For the laser light group, the plate was incubated for $6 \mathrm{~h}$ and exposed to laser light for $10 \mathrm{~min}$. For the dark group, the plate was also incubated for $6 \mathrm{~h}$ but without irradiation. Then, HeLa cells were stained with $0.5 \mathrm{~mL}$ of Hoechst $33342\left(10 \mu \mathrm{g} \mathrm{mL}{ }^{-1}\right)$ or $0.5 \mathrm{~mL}$ of PI $\left(10 \mu \mathrm{g} \mathrm{mL}{ }^{-1}\right)$ for $15 \mathrm{~min}$ in the darkness. Dual fluorescence-stained cultures were washed and the cells were observed and imaged using an inverted fluorescence microscope. All the experiments were carried out in triplicate.

To study the cellular uptake ability of 5 -FU/rGO/Bce, HeLa cells $\left(5 \times 10^{4}\right.$ per well) were seeded in 6-well plates and cultured in medium for $24 \mathrm{~h}\left(37^{\circ} \mathrm{C}, 5 \% \mathrm{CO}_{2}\right)$. After complete adhesion, the cells were washed twice with serum-free medium. Then, 3 $\mathrm{mL}$ of fresh serum-free medium containing $1 \mathrm{~mL}$ mixture of 5 -FU/rGO/Bce sol and fluorescein isothiocyanate (FITC)-dextran $\left(1 \mathrm{mg} \mathrm{mL}{ }^{-1}\right)$ was added and incubated at $37{ }^{\circ} \mathrm{C}$ for $1 \mathrm{~h}$. The remaining steps are similar to our previous work. ${ }^{28,37}$

\section{Results and discussion}

\subsection{Synthetic condition exploration and characterization of rGO/Bce hybrid hydrogel}

At the beginning of the experiment, we attempted to prepare novel and ideal $\mathrm{rGO} /$ Bce composites which could be preserved in the sol state at room temperature $\left(25^{\circ} \mathrm{C}\right)$ and transformed into a stable hydrogel quickly at body temperature $\left(37^{\circ} \mathrm{C}\right)$. Fig. 1 reveals the 

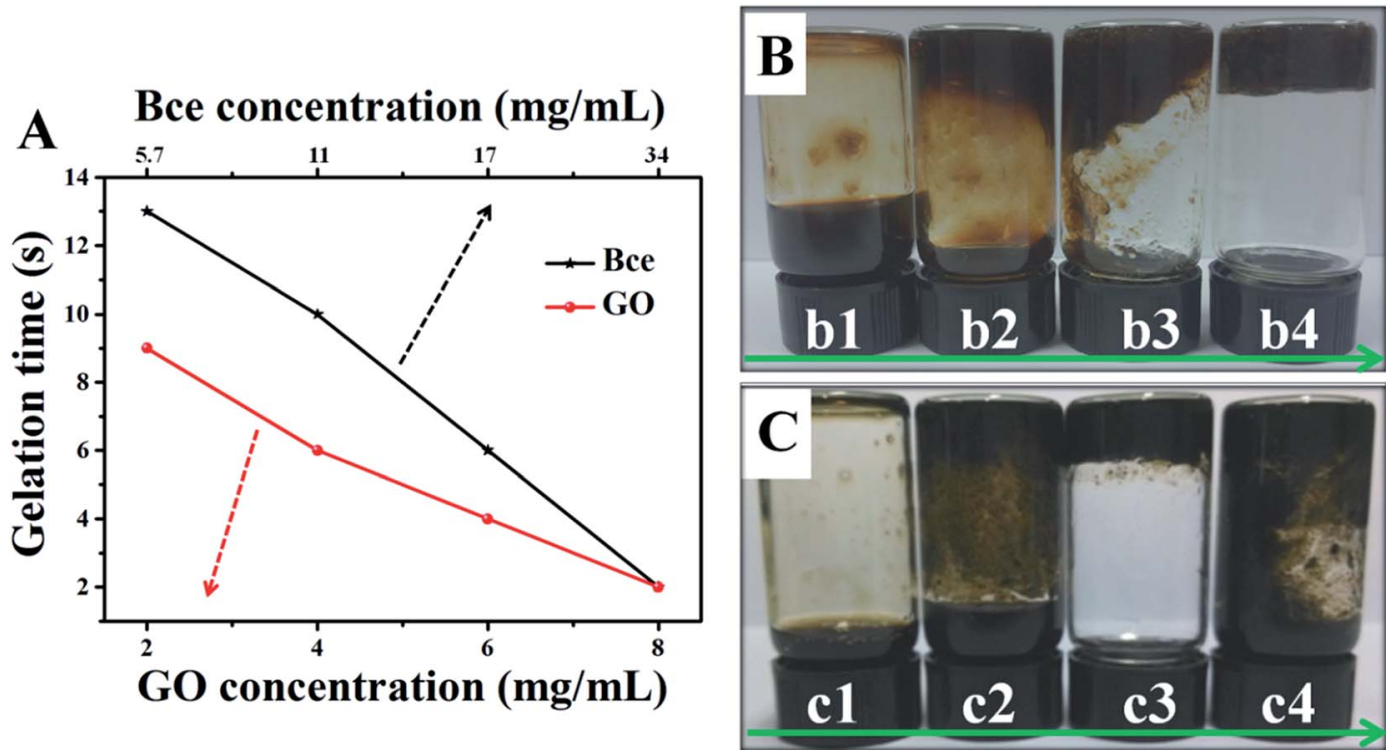

Fig. 1 (A) Effects of $\mathrm{GO}$ or Bce mass concentrations on the gelation time of $\mathrm{rGO} / \mathrm{Bce}$ at $25^{\circ} \mathrm{C}$. Digital photos of $\mathrm{rGO} / \mathrm{Bce}$ hybrid sol or hydrogel with different initial mixed $V_{\mathrm{GO}}: V_{\mathrm{Bce}}$ at (B) $25^{\circ} \mathrm{C}$ and (C) $37^{\circ} \mathrm{C}$ (before mixing, the concentrations of GO and Bce are $8 \mathrm{mg} \mathrm{mL}^{-1}$ and $34 \mathrm{mg} \mathrm{mL}^{-1}$, respectively. The $V_{\mathrm{GO}}: V_{\mathrm{Bce}}$ from (b1) or (c1) to (b4) or (c4) are $0.5: 1,1: 1,1.5: 1$, and $2: 1$, respectively).

effects of $\mathrm{GO}$ or Bce concentrations, $V_{\mathrm{GO}}: V_{\mathrm{Bce}}$ and temperature on the gelation time and the state of rGO/Bce hydrogel. From Fig. 1A, it is seen that the mixed systems have various gelation times with a change of the concentration of GO or Bce. While the GO mass concentration increased from 2 to $8 \mathrm{mg} \mathrm{mL} \mathrm{mL}^{-1}$ (Bce mass

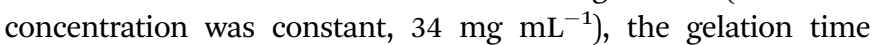
decreased from 9 to 2 s. Similarly, when the Bce mass concentration increased from 5.7 to $34 \mathrm{mg} \mathrm{mL}{ }^{-1}$ with the GO mass concentration $\left(8 \mathrm{mg} \mathrm{mL}^{-1}\right)$ unchanged, the gelation time varied from 13 to $2 \mathrm{~s}$. These results demonstrate that an increase of GO or Bce amount would be beneficial for the formation of the hydrogel. Based on the above experimental results, GO with a mass concentration of $8 \mathrm{mg} \mathrm{mL} \mathrm{m}^{-1}$ or Bce with a mass concentration of $34 \mathrm{mg} \mathrm{mL}^{-1}$ was chosen for further experiment. From Fig. 1B and $\mathrm{C}$, we can see the digital photos with different initial $V_{\mathrm{GO}}: V_{\mathrm{Bce}}$ at different temperatures. Obviously, the initial $V_{\mathrm{GO}}: V_{\mathrm{Bce}}$ also has an important effect on the production of hydrogel. We found that the optimum $V_{\mathrm{GO}}: V_{\mathrm{Bce}}$ is $0.5: 1$ (corresponding to the mass concentration ratio of $2: 17)$ for the formation of a flowable rGO/Bce sol at $25^{\circ} \mathrm{C}$ (Fig. 1B-b1) and $1.5: 1$ (corresponding to the mass concentration ratio of $6: 17$ ) for the formation of a fixed rGO/Bce hybrid hydrogel at $37{ }^{\circ} \mathrm{C}$ with the best morphological stability (Fig. 1C-c3). Thus, we could choose the relatively appropriate $V_{\mathrm{GO}}: V_{\mathrm{Bce}}$ in the range of $0.5: 1$ to $1.5: 1$.

The fast gelation of $\mathrm{rGO} / \mathrm{Bce}$ may be ascribed to the strong interaction between GO and Bce, including amide bond, $\pi-\pi$ stacking, hydrogen bonding, electrostatic attraction, etc., accompanied by the reduction of GO to rGO contributed to by a vitamin such as Vc or reducing amino acids in Bce, which was confirmed by following the XRD patterns, FTIR spectra, Raman spectra, HPLC chromatograms and so on.

Fig. 2A gives the XRD patterns of GO (a), Bce (b) and $\mathrm{rGO} / \mathrm{Bce}$ (c) hybrid hydrogel, respectively. As shown in Fig. 2A-a, pure GO reveals a sharp (002) diffraction peak at $2 \theta$ of $11.33^{\circ}$, relating to a layer-to-layer stacking distance of $7.82 \AA{ }^{38}$ Fig. 2A-b shows the XRD pattern of the Bce, demonstrating that bio-molecules in Bce are amorphous. The broad (002) diffraction peak around $27.24^{\circ}$ that appears in Fig. 2A-c indicates that the interlayer distance of $\mathrm{rGO} /$ Bce decreased to $3.34 \AA$ A, suggesting an ample reduction of GO by Bce.

The FT-IR spectra of GO, Bce, and rGO/Bce hybrid hydrogel are shown in Fig. 2B-a-c, respectively. In the case of GO (Fig. 2Ba), an intense and broad band is observed at about 3200-3400 $\mathrm{cm}^{-1}$ due to the $\mathrm{O}-\mathrm{H}$ stretching vibrations arising from hydroxyl groups in GO. The absorption at $1725 \mathrm{~cm}^{-1}$ is the characteristic band of $\mathrm{C}=\mathrm{O}$ groups in carbonyl and carboxyl moieties. The three characteristic absorbance peaks of Bce at 1636, 1520 and $1246 \mathrm{~cm}^{-1}$ in Fig. 2B-b are assigned to the $\mathrm{C}-\mathrm{O}$ stretching vibration of -NHCO- (amide I), the $\mathrm{N}-\mathrm{H}$ bending vibration of $-\mathrm{NH}_{2}$ (amide II) and the $\mathrm{C}-\mathrm{N}$ bending vibration of -NHCO- (amide III), ${ }^{25,39}$ indicating the existence of proteins in Bce. The bands at $1079 \mathrm{~cm}^{-1}$ and $1400 \mathrm{~cm}^{-1}$ could be attributed to the $\mathrm{C}-\mathrm{O}-\mathrm{C}$ group of chlorophyll, reducing vitamin $(\mathrm{Vc})$ and polypeptide amino acid, etc. After GO was mixed with Bce, the FTIR spectrum of the obtained $\mathrm{rGO} /$ Bce hybrid hydrogel from Fig. 2B-c reveals the disappearance of the $-\mathrm{COOH}$ group of GO at $1725 \mathrm{~cm}^{-1}$, and the broadening of the amide I band at $\sim 1636 \mathrm{~cm}^{-1}$. Meantime, the peak intensity of the acetylated amino group -NHCO- (amide II and amide III) decreased. The above peak changes disclose that there were strong interactions between the polar groups of GO and Bce, which act as crosslink agents for the reduction of GO and the formation of the $\mathrm{rGO} / \mathrm{Bce}$ hybrid hydrogel.

The Raman spectra of GO and the rGO/Bce hybrid hydrogel are shown in Fig. 2C, which could further demonstrate the reduction of GO and successful fabrication of the $\mathrm{rGO} / \mathrm{Bce}$ hydrogel. Two strong peaks at $1355 \mathrm{~cm}^{-1}$ and $1593 \mathrm{~cm}^{-1}$ assigned to the typical $\mathrm{D}$ and $\mathrm{G}$ bands of $\mathrm{GO}^{\mathbf{4 0}}$ are shown in 

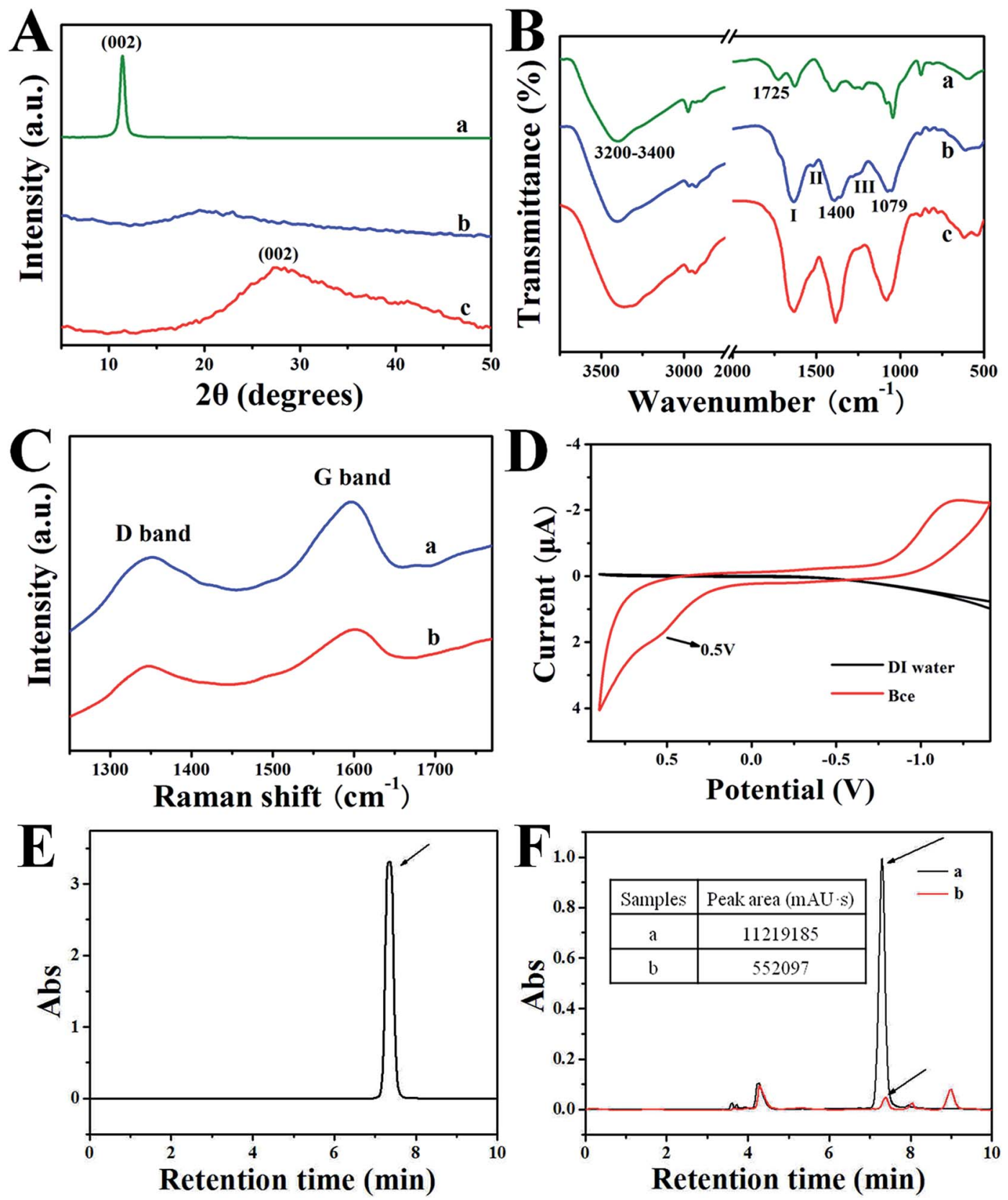

Fig. 2 (A) XRD patterns and (B) FT-IR spectra of GO (a), Bce (b) and rGO/Bce hydrogel (c). (C) Representative Raman spectra of (a) GO and (b) $\mathrm{rGO} /$ Bce hydrogel. (D) Cyclic voltammogram of Bce and pure water recorded at a scan rate of $0.02 \mathrm{~V} \mathrm{~s}^{-1}$ in the potential window between -1.50 and $0.90 \mathrm{~V}$. (E) HPLC chromatogram of standard Vc. (F) HPLC chromatograms of (a) Bce and (b) rGO/Bce. The inset in (F) presents the peak areas of (a) Bce and (b) rGO/Bce. Arrows indicate the peaks from the $\mathrm{V}_{\mathrm{c}}$.

Fig. 2C-a. However, the corresponding two bands for the rGO/ Bce hydrogel from Fig. 2C-b display a small red-shift to 1347 $\mathrm{cm}^{-1}$ and a small blue-shift to $1600 \mathrm{~cm}^{-1} \cdot{ }^{41}$ The spectral shifts could be ascribed to the disturbance of the GO structure caused by physical or chemical interactions between the epoxy, hydroxyl, and carboxyl moieties of GO and polar groups of Bce, such as the amino, carboxyl, acylamino and alkoxy groups. At the same time, the $I_{\mathrm{D}} / I_{\mathrm{G}}$ value of the $\mathrm{rGO} / \mathrm{Bce}$ hybrid hydrogel decreased from 0.81 to 0.78 in comparison with that of the GO (Fig. S1†). These results can be attributed to the processes of the relatively green and facile chemical reduction of GO compared with solvothermal method ${ }^{\mathbf{4 2}}$ and the strong bonding effect of GO and Bce.

We also examined the electrochemical behavior of Bce to determine the role of Bce as a reducing agent. Fig. 2D shows a typical cyclic voltammogram of the Bce, which was recorded at a scan rate of $0.02 \mathrm{~V} \mathrm{~s}^{-1}$ in the potential window between -1.50 and $0.90 \mathrm{~V}$. It can be seen clearly from the black line in Fig. 2D that there is no redox activity at the Pt electrode in pure water in the potential range. However, an oxidation peak at the potential of about $0.50 \mathrm{~V}$ in the Bce can be seen, ${ }^{43}$ indicating the occurrence of an oxidation reaction for Bce, which possibly arose 
from the reducing activity of the hydrosulfuryl, hydroxyl and amino groups from vitamins such as Vc or reducing amino acids in the Bce. According to our investigations, Vc, as a strong reducing agent, has a similar electrochemical behavior to that of Bce (from a previous report). ${ }^{44}$ Thus, we hypothesized that Vc may play a major role in the formation of a $\mathrm{rGO} / \mathrm{Bce}$ hydrogel.

To further confirm the above speculation, a HPLC method was chosen to measure the changes of Vc content in Bce before and after the addition of GO. Fig. 2E shows an HPLC chromatogram of the Vc standard detected by the absorbance at $242 \mathrm{~nm} .{ }^{45}$ The retention time of the Vc was $7.3 \mathrm{~min}$. A typical chromatogram of the Vc in Bce is also observed in Fig. 2F-a with a peak area of 11219185 mAU s. We can also see from Fig. 2Fa that the contents of other compositions in Bce are relatively much less than that of Vc. After the addition of a GO dispersion, the peak of Vc shown in Fig. 2F-b is greatly decreased compared with the peak area of 552091 mAU s. Therefore, the reduction effect of Bce to GO is also demonstrated by the decrease in peak area of Vc detected at $242 \mathrm{~nm}$. We can conclude that Vc played an important role in the formation of the $\mathrm{rGO} / \mathrm{Bce}$ hydrogel.

By SEM observation (Fig. 3), we found that there were some obvious differences between the morphologies of GO and the rGO/Bce hybrid hydrogel. Fig. 3A shows a wrinkled paper-like morphology of GO. In addition, the AFM image of GO nanosheets on the mica wafer is presented in Fig. S2-A, $\uparrow$ showing that GO nanosheets have an irregular shape with the plane sizes in the range from tens to thousands of nanometers and an average thickness of $\sim 1.3 \mathrm{~nm}$ (ref. 25) (Fig. S2-B†), which is the characteristic thickness of single-layer GO nano-sheets. Compared with pure GO, a 3-D porous network structure is found in the $\mathrm{rGO} / \mathrm{Bce}$ hybrid hydrogel with an average pore size of $\sim 30 \mu \mathrm{m}$ (Fig. 3B and the corresponding inset (a)), which is attributed to the thicker layers of stacked GO nano-sheets through strong interactions between the GO and Bce.

\subsection{Photodynamic and photothermal effect}

As shown in Fig. 4A, the UV-Vis absorption spectra of GO, Bce, $\mathrm{rGO} / \mathrm{Bce}$ and DPBF were measured for the exploration of $\mathrm{rGO} /$ Bce as a photodynamic agent. The peak of GO (black curve) at $233 \mathrm{~nm}$ corresponds to the $\pi \rightarrow \pi^{*}$ transition of the $\mathrm{C}=\mathrm{C}$ bond. Bce (red curve) exhibits a characteristic absorption band of chlorophyll at 650-680 nm (ref. 46) and other components, such as Vc in Bce, could be attributed to the absorption band at 250$400 \mathrm{~nm} . .^{45}$ In the UV-Vis absorption spectrum of the rGO/Bce hybrid hydrogel (blue curve), we observe not only the

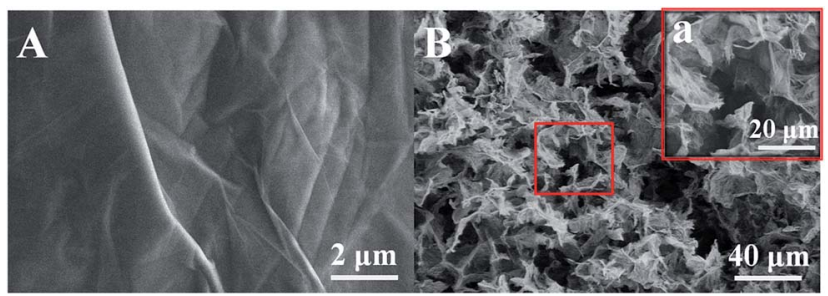

Fig. 3 SEM images of (A) GO and (B) the $\mathrm{rGO/Bce} \mathrm{hydrogel.} \mathrm{Inset} \mathrm{(a)} \mathrm{in}$ $(B)$ is the corresponding partial high magnification version. characteristic band of Bce, but also a change in the GO peak due to the reduction of GO, which confirms the presence of rGO and Bce in the hybrid hydrogel. The characteristic absorption peak of DPBF at $410 \mathrm{~nm}$ can be seen from the dark cyan curve in Fig. 4A, which is a non-overlapping peak compared with other reactants and available for monitoring the production of ${ }^{1} \mathrm{O}_{2}$.

The ${ }^{1} \mathrm{O}_{2}$ generation that may be induced by the GO, Bce and $\mathrm{rGO} / \mathrm{Bce}$ systems is very important for PDT. DPBF reacts with ${ }^{1} \mathrm{O}_{2}$ irreversibly and undergoes a 1,4-cycloaddition reaction that is detected as a decrease in the absorption intensity of the DPBF at $410 \mathrm{~nm} .^{25}$ The UV-Vis spectrum changes of the mixed GO/ DPBF system are shown in Fig. 4B; it is seen that the DPBF absorption peak at $410 \mathrm{~nm}$ has no significant decline with laser irradiation $(650 \mathrm{~nm}$ ) for $20 \mathrm{~s}$. However, we clearly observe that the absorption peak intensity of the Bce/DPBF (Fig. 4C) or $\mathrm{rGO} /$ Bce/DPBF (Fig. 4D) system at about $410 \mathrm{~nm}$ is rapidly weakened, demonstrating that ${ }^{1} \mathrm{O}_{2}$ was generated quickly and DPBF was consumed fast, suggesting that Bce/DPBF or $\mathrm{rGO} / \mathrm{Bce} / \mathrm{DPBF}$ used to determine the production of ${ }^{1} \mathrm{O}_{2}$ is available and the efficient generation of ${ }^{1} \mathrm{O}_{2}$ in the photosensitized process is mainly due to the contribution of Bce and not of GO. To further confirm the results of the DPBF experiments, ESR spin trapping spectroscopy for Bce was measured. ${ }^{1} \mathrm{O}_{2}$ can be measured by ESR because it can oxidize TEMP to form the stable $N$-oxyl radical TEMPO. The characteristic symmetrical triplet of the paramagnetic TEMPO ESR spectrum ${ }^{47}$ is obviously observed from Fig. 4E. The signal of ${ }^{1} \mathrm{O}_{2}$ production further indicates that Bce can be used in PDT. These results suggest that the $\mathrm{rGO} / \mathrm{Bce}$ hybrid hydrogel can act as an effective photodynamic agent for the release of ${ }^{1} \mathrm{O}_{2}$ to kill tumor cells.

We also investigated the potential use of $\mathrm{rGO} /$ Bce as a photothermal agent. The red curve of $\mathrm{rGO} /$ Bce in Fig. $4 \mathrm{~F}$ presents a rapid temperature increase during the initial irradiation for $4 \mathrm{~min}$ and a slow temperature variation from 4 to $10 \mathrm{~min}$. The total temperature increase of $\mathrm{rGO} / \mathrm{Bce}$ hydrogel is up to $17^{\circ} \mathrm{C}$ within $11 \mathrm{~min}$, whereas the water temperature increases by only $3{ }^{\circ} \mathrm{C}$ under the same laser exposure. The IR-thermal images of water and the rGO/Bce hybrid hydrogel exposed to the laser for 11 min are shown in insets (a) and (b) in Fig. 4F, which demonstrate the temperatures at $28{ }^{\circ} \mathrm{C}$ and $42{ }^{\circ} \mathrm{C}$, respectively. These results further confirm that the $\mathrm{rGO} / \mathrm{Bce}$ hybrid hydrogel has a good photo-thermal effect and could serve as a synergistic platform for PDT/PTT with an efficient therapy.

\subsection{Loading and release of 5-FU}

The loading of 5-FU of different concentrations in a GO dispersion is demonstrated by the UV-Vis absorbance spectra of the samples (Fig. 5A), wherein the calibration curve (Fig. S3†) was obtained with $5-\mathrm{FU} / \mathrm{HCl}$ solutions at different 5 -FU concentrations to calculate the L.E. As shown in Fig. 5A, the UVVis spectra of all the samples display a typical 5FU peak with different densities at $266 \mathrm{~nm}$, which indicates the successful loading of 5FU in GO with different L.E.s through hydrophilic interaction or $\pi-\pi$ cooperative interactions between $5 \mathrm{FU}$ and GO. The drug loading results show that the L.E. of GO for 5FU increased from $16.2 \%$ to $48.4 \%$ with increased 5 -FU amounts 

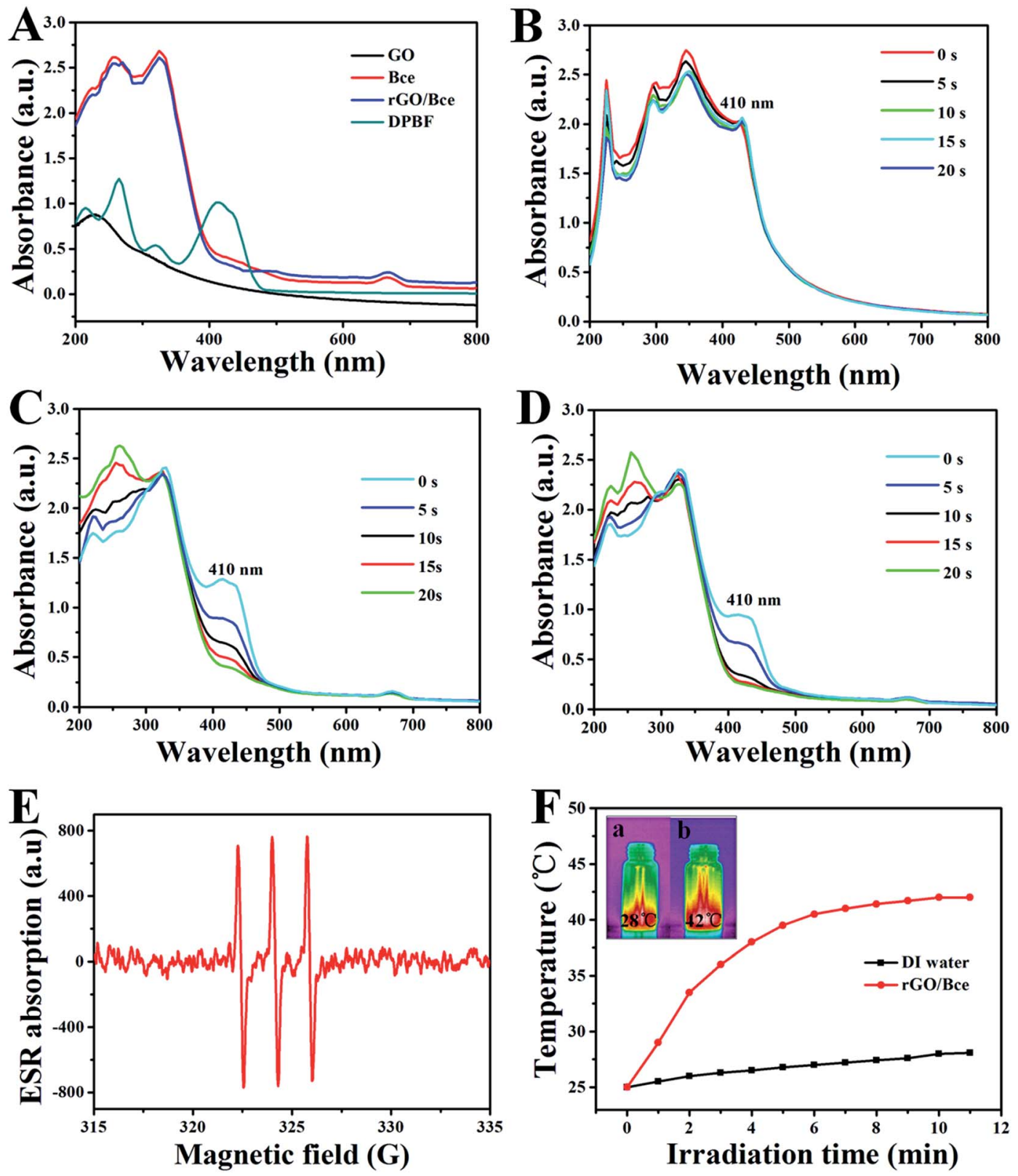

Fig. 4 (A) UV-Vis absorption spectra of GO, Bce, $\mathrm{rGO} / \mathrm{Bce}$ and DPBF. Photobleaching of DPBF $\left(0.196 \mathrm{~g} \mathrm{~mL}^{-1}\right)$ via the generation of ${ }^{1} \mathrm{O}_{2}$ in the presence of (B) GO, (C) Bce, and (D) rGO/Bce with different irradiation times at a wavelength of $650 \mathrm{~nm}$. (E) ESR detection of ${ }^{1} \mathrm{O}_{2}$ for $\mathrm{Bce}$. (F) Temperature changes of DI water and $\mathrm{rGO} / \mathrm{Bce}$ with $808 \mathrm{~nm}$ laser irradiation at a power density of $1 \mathrm{~W} \mathrm{~cm}{ }^{-2}$ for different lengths of time. The insets in (F) are the corresponding thermal infrared images of (a) DI water and (b) rGO/Bce after irradiation for 11 min under the same conditions.

from 1 to $4 \mathrm{mg} \mathrm{mL}{ }^{-1}$. For the hybrid hydrogel prepared with different 5-FU amounts, the in vitro release profiles of encapsulated 5-FU were investigated in phosphate buffer $(\mathrm{pH} 7.4)$ at $37{ }^{\circ} \mathrm{C}$, shown in Fig. 5B, which indicates a sustained 5-FU release behavior in every case. More importantly, the drug release rate is found to decrease with the increased 5 -FU amount from 1 to $4 \mathrm{mg} \mathrm{mL}^{-1}$, so it seems that the drug release behavior can be tuned easily by changing the amounts of 5 -FU.

The initial volume ratio of $V_{5-\mathrm{FU} / \mathrm{GO}}: V_{\mathrm{Bce}}$ was chosen to further investigate the influence of 5-FU loading on the stability of the hybrid sol or hydrogel. Fig. 6 reveals the state of the 5-FU/ rGO/Bce hybrid sol or hydrogel with different initial
$V_{\text {5-FU/GO }}: V_{\text {Bce }}$ at room temperature $\left(25^{\circ} \mathrm{C}\right)$ and simulative body temperature $\left(37^{\circ} \mathrm{C}\right)$. Obviously, the optimum $V_{5-\mathrm{FU} / \mathrm{GO}}: V_{\mathrm{Bce}}$ is $1.5: 1$ (corresponding to the mass concentration ratio of $6: 17$ ) for the formation of a 5-FU/rGO/Bce hybrid hydrogel at $37^{\circ} \mathrm{C}$, which is similar to the results of Fig. 1. Comparing Fig. $1 \mathrm{~B}$ or $\mathrm{C}$ with Fig. 6A or B, we can also find out that the loading of 5-FU to $\mathrm{rGO} / \mathrm{Bce}$ has an inconspicuous effect on the stability of the 5FU/rGO/Bce sol or hydrogel. Thus, we can directly inject the 5$\mathrm{FU} / \mathrm{rGO} / \mathrm{Bce}$ sol with $V_{5-\mathrm{FU} / \mathrm{GO}}: V_{\mathrm{Bce}}$ in the range $0.5: 1$ to $1.5: 1$ at room temperature into the lesion site to form a hydrogel through minimally invasive surgery at body temperature. 

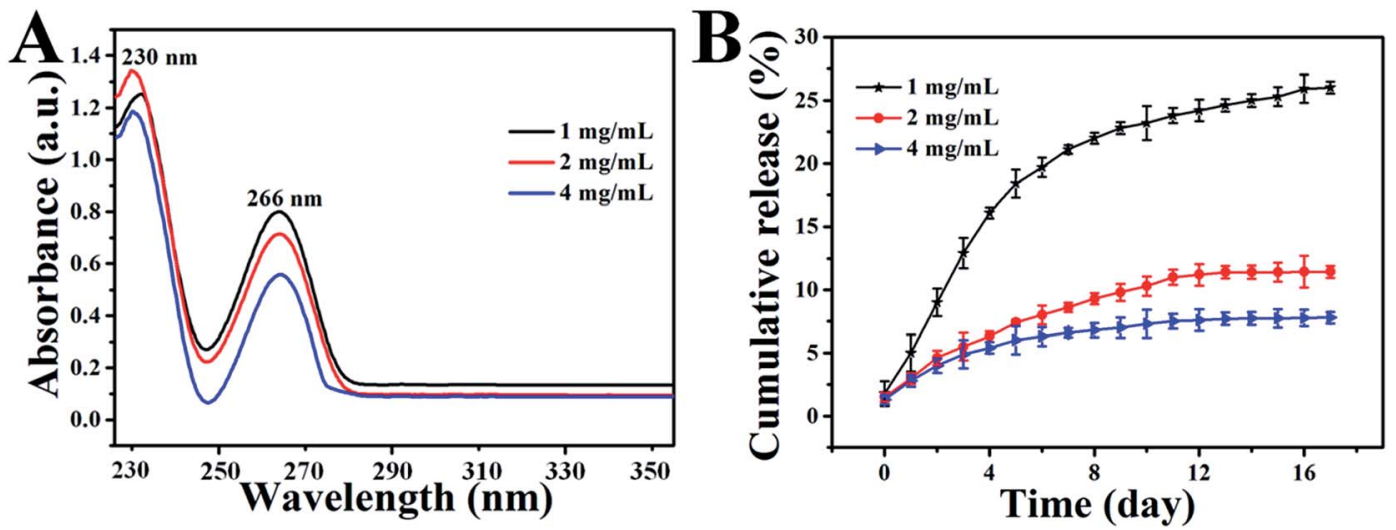

Fig. 5 (A) UV-Vis absorption spectra of 5-FU solutions of different concentrations after being loaded in a $\mathrm{GO}$ dispersion (8 $\mathrm{mg} \mathrm{mL}^{-1}$ ). (B) $/ \mathrm{n}$ vitro release profiles of loaded 5-FU from the 5-FU/rGO/Bce hybrid hydrogel prepared with different amounts of 5-FU in phosphate buffer (pH 7.4) at $37^{\circ} \mathrm{C}$. Error bars are based on the standard deviation (SD) of triplicate samples.

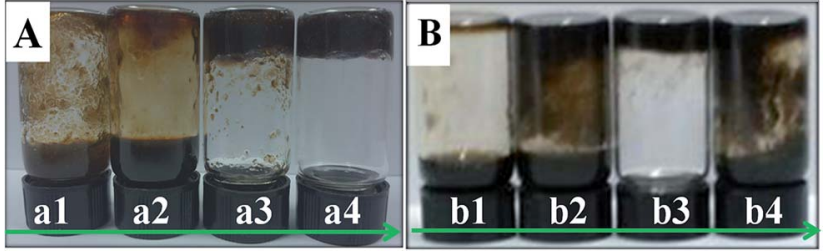

Fig. 6 Digital photos of the 5-FU/rGO/Bce hybrid sol or hydrogel with different initial mixed $V_{5-F U / G O}: V_{\text {Bce }}$ values at (A) $25^{\circ} \mathrm{C}$ and (B) $37^{\circ} \mathrm{C}$ (before mixing, the concentrations of the initial $5-\mathrm{FU}, \mathrm{GO}$ and Bce were $2 \mathrm{mg} \mathrm{mL}^{-1}, 8 \mathrm{mg} \mathrm{mL}^{-1}$ and $34 \mathrm{mg} \mathrm{mL}^{-1}$, respectively. The $V_{5-F U / G O}: V_{\text {Bce }}$ from (a1) or (b1) to (a4) or (b4) are $0.5: 1,1: 1,1.5: 1$, and $2: 1$, respectively)

\subsection{The formation and mechanism analysis of the hybrid} hydrogel shell on the tumor cells

Combining the above experimental results, the formation process of the 5 -FU/rGO/Bce hybrid hydrogel on the HeLa cell surface is illustrated in Scheme 1. The Bce as a crosslinking agent containing vitamins, multi-amino carbohydrates, amino acids or proteins can be combined with GO nanosheets through amide bond, hydrogen bonds, electrostatic attraction, etc., and a reducing agent to reduce $\mathrm{GO}$ to $\mathrm{rGO}$, which could be seen from the color change of the GO dispersion (brown) to rGO/Bce hydrogel (black). Firstly, a flowable 5-FU/rGO/Bce sol was fabricated at $25{ }^{\circ} \mathrm{C}$ by stirring a mixture of 5-FU, GO and Bce. Subsequently, HeLa cells were cultured with the 5-FU/rGO/Bce sol at body temperature $\left(37^{\circ} \mathrm{C}\right)$, and the stable hybrid hydrogel shells rapidly and easily formed on the surface of the cells in situ, which can both retain the concentration of chemotherapeutic drug (5-FU), photo-thermal agent (rGO) and photosensitizer (Bce) around the tumor cells, and prevent them from diffusing to normal tissue. Finally, the tumor cells are killed by the ${ }^{1} \mathrm{O}_{2}$ released from Bce and oxygen, the local increased temperature under NIR irradiation and 5-FU from the 5-FU/rGO/Bce hydrogel shell. The hybrid hydrogel shows prominent enhanced and synergistic antitumor effects with a combination of PDT, CT and PTT, and may be a potential method for cancer treatment through successive and artificially controlled irradiation.

The formation of the hybrid hydrogel on the surface of HeLa cells in situ was investigated by optical microscope photos and fluorescence images (Fig. 7). The microscopic images of the HeLa cells in the absence or presence of 5 -FU/rGO/Bce hybrid hydrogel encapsulation are shown in Fig. 7A and B. It can be seen from Fig. 7B that the surface of the HeLa cells is covered with a thin and semitransparent shell compared with those in Fig. 7A. Fig. 7C shows a fluorescence microscopy image of HeLa cells encapsulated with hydrogel shells stained by Hoechst 33342, and Fig. 7D presents the merged image of Fig. 7B and C. Thus, a firm and apparent hydrogel shell (indicated by red arrows) on the HeLa cells can be seen more clearly from Fig. 7D. The results indicate that the hydrogel shell can be easily and successfully formed on the HeLa cells in situ.

\subsection{Cytotoxicity assay and uptake studies}

The relative viabilities of HeLa cells and $\mathrm{CHO}$ cells cultured with $\mathrm{rGO} / \mathrm{Bce}$ and the 5-FU/rGO/Bce hybrid hydrogel in the presence or absence of irradiation were examined via the standard MTT assay, as shown in Fig. 8. From Fig. 8A, as expected, the cell survival rates with all the samples show a downward trend as the concentration of the samples increased, indicating the dose-effect relation among them. When the dispersions of $\mathrm{rGO} /$ Bce and 5-FU/rGO/Bce were not diluted by culture medium with the concentration of $a\left(34 \mathrm{mg} \mathrm{mL}^{-1}\right)$, the relative cell survival rates in the absence of irradiation were $95.3 \%$ and $86.5 \%$, respectively. The above results indicate that $\mathrm{rGO} / \mathrm{Bce}$ has low cytotoxicities and 5-FU can prompt the apoptosis of HeLa cells. However, after 5 minutes of sequential laser radiation, the relative viabilities of HeLa cells incubated with $\mathrm{rGO} /$ Bce and 5 -FU/rGO/Bce hybrid hydrogel at the concentration of $34 \mathrm{mg}$ $\mathrm{mL}^{-1}$ sharply decreased to $77.1 \%$ and $60.3 \%$, respectively, revealing that the laser radiation can accelerate the death of HeLa cells due to the photodynamic effect of Bce and photothermy of $\mathrm{rGO}$, and the $5-\mathrm{FU} / \mathrm{rGO} / \mathrm{Bce}$ hybrid hydrogel system can serve as a synergistic high-performance platform by 


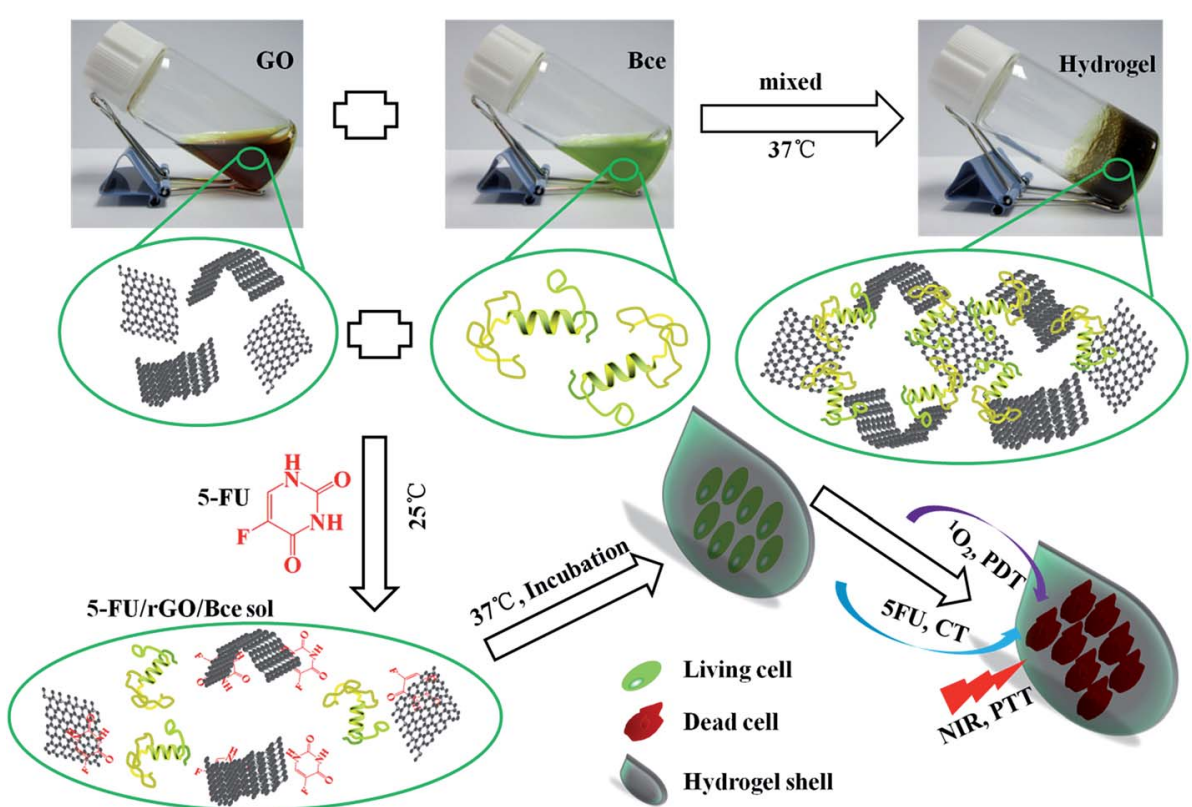

Scheme 1 Schematic diagrams of the fabrication process for the 5-FU/rGO/Bce hybrid hydrogel and the antitumor mechanism of the 5-FU/ $\mathrm{rGO} /$ Bce hybrid hydrogel shell formed on the HeLa cells.

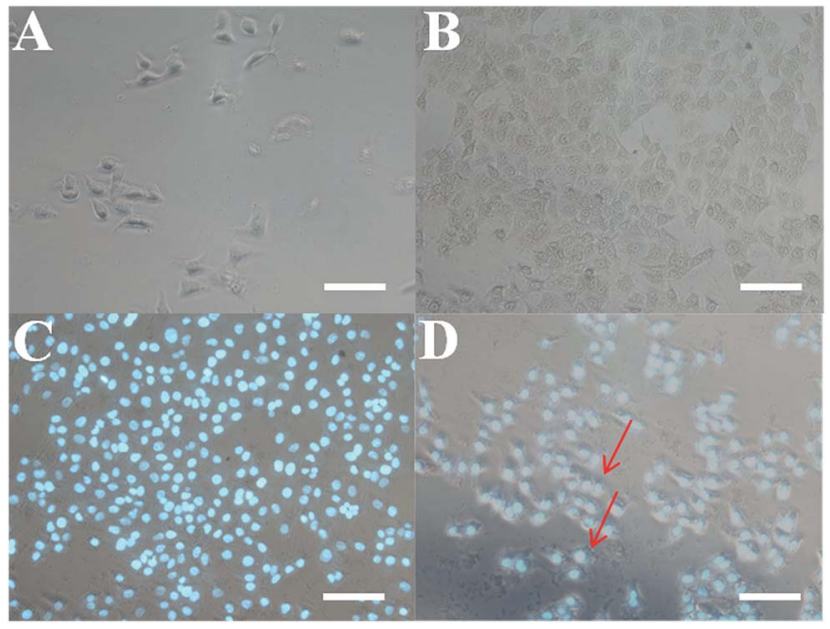

Fig. 7 Optical microscope images of (A) bare HeLa cells and (B) HeLa cells encapsulated with 5-FU/rGO/Bce hybrid hydrogel shells. (C) Fluorescence microscopy image of HeLa cells with Hoechst 33342 staining encapsulated with hybrid hydrogel shells. (D) Merged image of images $(B)$ and $(C)$; red arrows indicate hybrid hydrogel shells. The scale bars are $100 \mu \mathrm{m}$.

combing PDT, PTT and CT for cancer treatment. We also investigated the effect of samples to normal cells (CHO cells). From Fig. 8B, a similar dose dependent cytotoxicity behavior is observed on CHO cells, but the effect is smaller than that for HeLa cells, which also indicates that rGO/Bce is biocompatible with low cytotoxicity on normal cells. After irradiation for rGO/Bce, decreased viabilities of $\mathrm{CHO}$ cells were observed, indicating the similar anti-cell effect of PDT and PTT to CHO cells. However, for the 5-FU/rGO/Bce to $\mathrm{CHO}$ cells group, the side effects are smaller than those for the HeLa cells (Fig. 8A), which may be attributed to the poor internalization ability of $5-\mathrm{FU} / \mathrm{rGO} /$ Bce into $\mathrm{CHO}$ cells with the absence of some receptor such as folate or an epidermal growth factor receptor on the $\mathrm{CHO}$ cell surface. ${ }^{48}$ Obviously, the 5 -FU/rGO/Bce is a promising injectable biomaterial and could rapidly form hydrogel shells around cancer cells through local injection to enhance the effect on a localized antitumor. The side effects for the normal tissues outside of the hydrogel shell would be reduced because the dense structure of hydrogel shell could hinder drugs from external leakage. As a result, the 5-FU/rGO/Bce could kill more cancer cells and reduce the damage to normal cells through the way of tumor injection.

Fluorescence images of HeLa cells under different conditions are shown in Fig. 9, which are used to further illustrate the bio-compatibility and antitumor activity of the hybrid hydrogel. For HeLa cells incubated with nothing or rGO/Bce without irradiation, cell deaths are both difficult to observe (essentially no red in Fig. 9A2 and B2) due to the favorable biocompatibility of the $\mathrm{rGO} /$ Bce hydrogel. Fig. 9C shows cells incubated with the 5-FU/rGO/Bce without irradiation; some cells appear stained by PI (red fluorescence in Fig. 9C2), indicating the toxicity of the released 5-FU from 5-FU/rGO/Bce, in agreement with the MTT results. More dead cells stained by PI (faint red fluorescence signals in Fig. 9D2) could be seen from the rGO/Bce experimental group with irradiation, which reveals that Bce and rGO irradiated by laser can induce the generation of ${ }^{1} \mathrm{O}_{2}$ and hyperthermia to kill HeLa cells together. Among Fig. 9C-E, the strongest red fluorescence images of HeLa cells incubated with 5 -FU/rGO/Bce in the presence of laser irradiation can be observed in Fig. 9E2 and E3. Such a fact demonstrates that the antitumor effect of the 5-FU/rGO/Bce hybrid hydrogel under irradiation is much higher than that without irradiation, suggesting multimodel synergetic therapies, such as CT, PDT and PTT due to the coexistence of 5-FU, rGO and Bce, are superior to 

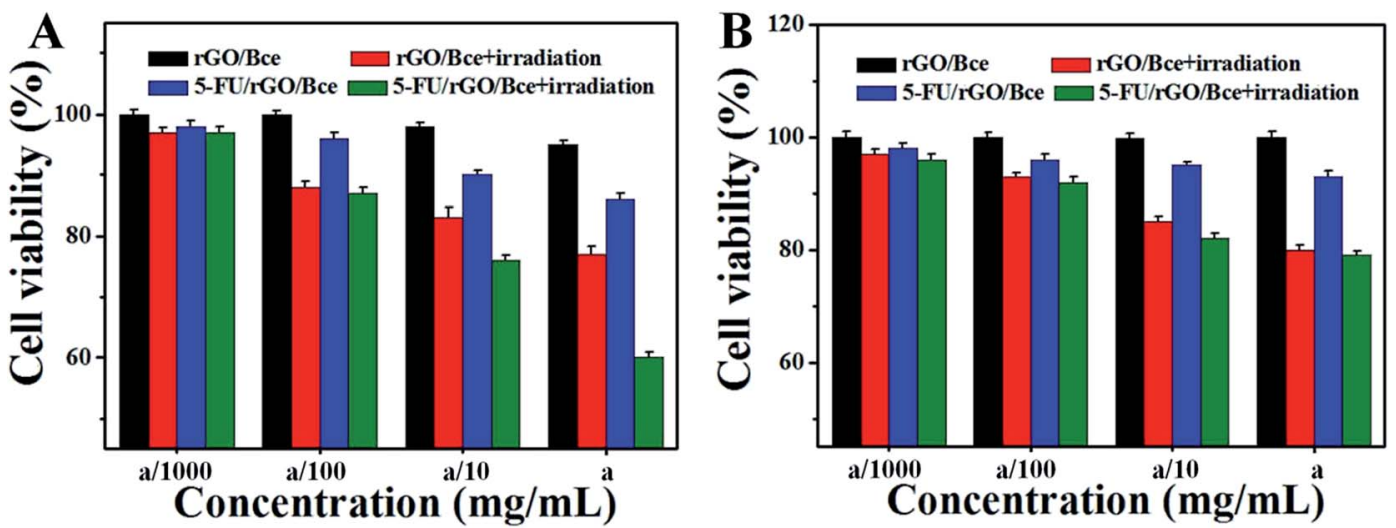

Fig. 8 Viabilities of (A) HeLa cells and (B) CHO cells in the presence of $\mathrm{rGO} /$ Bce and the 5-FU/rGO/Bce hybrid hydrogel with or without irradiation. The concentrations of Bce in $\mathrm{rGO} /$ Bce and in $5-\mathrm{FU} / \mathrm{rGO} / \mathrm{Bce}$ are all a (34 $\mathrm{mg} \mathrm{mL}^{-1}$ ). Error bars are based on the standard deviation (SD) of triplicate samples.

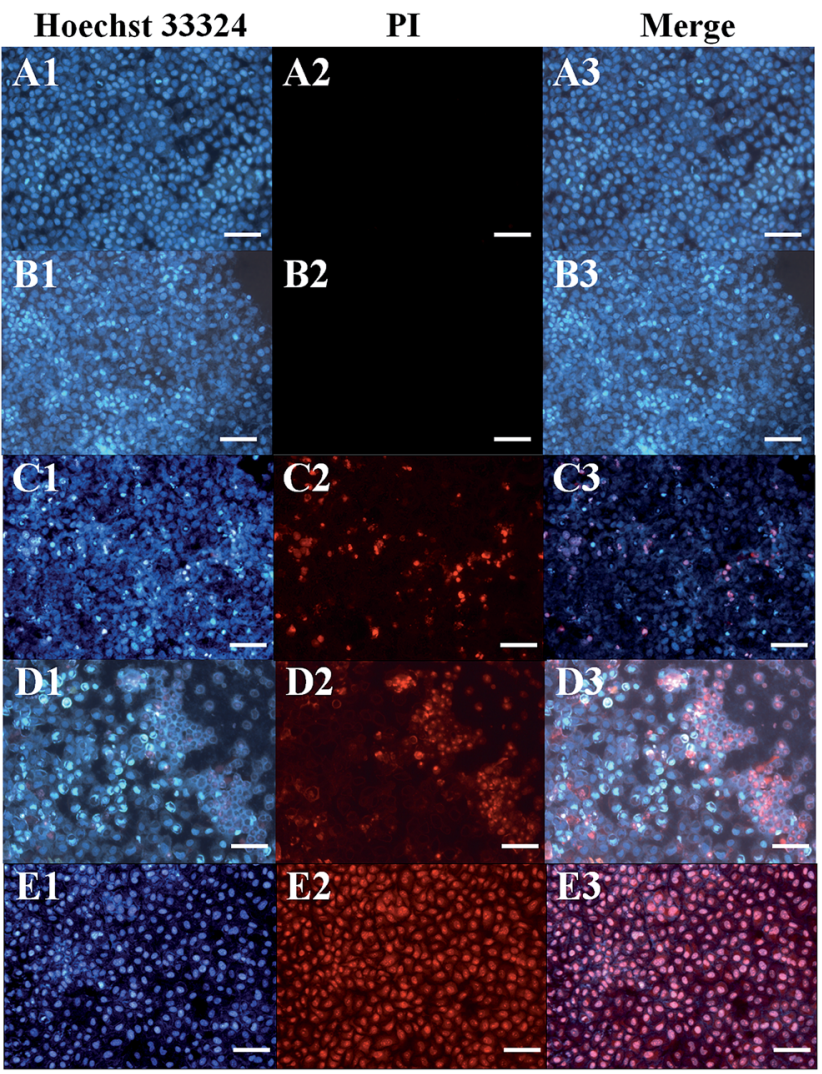

Fig. 9 Fluorescence microscopy images of HeLa cells incubated with (A) nothing, (B) $\mathrm{rGO} / \mathrm{Bce}$ or (C) the $5-\mathrm{FU} / \mathrm{rGO} / \mathrm{Bce}$ hybrid hydrogel without irradiation, and (D) $\mathrm{rGO} / \mathrm{Bce}$ or (E) the 5-FU/rGO/Bce hybrid hydrogel after irradiation for $5 \mathrm{~min}$. Each series can be classified by the cell nucleus dyed in blue by Hoechst 33342 (left), red by PI (middle) and the merged images of both the above (right). The scale bars are $100 \mu \mathrm{m}$.

a single one for cancer treatment. As a result, the hydrogel system may be used in localized collaborative treatment for cancer.

FITC-dextran notation can monitor samples in and out of the cell membrane, so we use FITC-dextran to label the $5-\mathrm{FU} / \mathrm{rGO} / \mathrm{Bce}$ hybrid hydrogel. Fig. 10A shows the image of

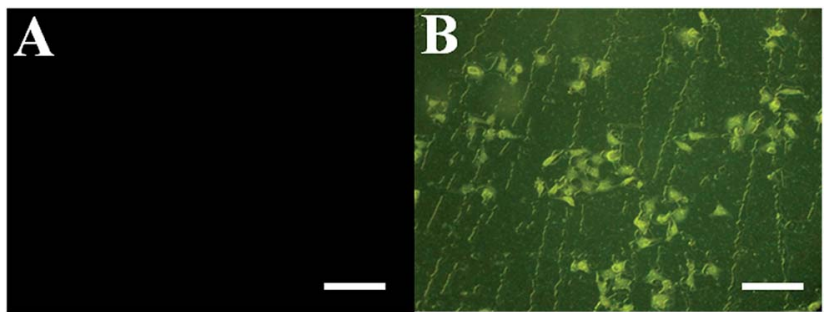

Fig. 10 Fluorescence microscopy images of (A) FITC-dextran with HeLa cells and (B) FITC-dextran labeled 5-FU/rGO/Bce with HeLa cells. The scale bars are $50 \mu \mathrm{m}$.

FITC-dextran with HeLa cells, there is almost no fluorescence within the cells. However, after incubation with the FITCdextran-labeled 5-FU/rGO/Bce hybrid hydrogel, an intense green fluorescence is clearly visible in the entire cell with laser excitation (Fig. 10B). This contrast result could be explained by the multi-interactions (hydrogen bonding, van der Waals forces, hydrophobic interactions, etc.) between the 5 -FU/rGO/Bce hybrid hydrogel and sugar chains or phospholipid molecules on the cell membrane, such that the $5-\mathrm{FU} / \mathrm{rGO} / \mathrm{Bce}$ hybrid hydrogel can induce the destabilization of the lipid bilayer membrane and then act as a trans-membrane carrier to increase the internalization of $5-\mathrm{FU} / \mathrm{rGO} / \mathrm{Bce}$ in the cells, which will be favorable for a dense distribution of drugs, including 5-FU, photosensitizers and photothermal agents, on lesions and hinder their migration to normal tissue at the same time, and thereby strengthen the therapeutic effect.

\section{Conclusions}

In the present study, a novel 5-FU/rGO/Bce hybrid hydrogel with effective localized and cooperative antitumor properties can be facilely synthesized by reduction and crosslinking of GO with Bce. The rGO/Bce hybrid hydrogel presents good biocompatibility due to the green and eco-friendly Bce and nontoxic rGO. The Bce could cause the release of ${ }^{1} \mathrm{O}_{2}$ as a photosensitizer while rGO could produce a laser-induced 
thermal effect by laser irradiation, both characteristics that could be used to cooperatively kill tumor cells. In addition, this hybrid hydrogel also could load 5-FU to play the role of a CT for synergistic antitumors with PTT and PDT. The one-step synthesis of the bio-functional $5-\mathrm{FU} / \mathrm{rGO} / \mathrm{Bce}$ inorganicbiochemical hybrid hydrogels reported here is completely green, eco-friendly and easy to scale up. This approach could be expanded to other anti-neoplastic agents for antitumor applications.

\section{Acknowledgements}

This work is supported by the National Nature Science Foundation of China (51372004, 21571002 and 21371003), and the Anhui Province Key Laboratory of Environment-Friendly Polymer Materials.

\section{References}

1 R. K. Rovere and A. S. De Lima, Klin. Onkol., 2015, 28, 370372.

2 T. Wu, A. J. Munro, G. Liu and J. L. Guan, Cochrane Database Syst. Rev., 2005, 5, 85-86.

3 L. Bingle, N. J. Brown and C. E. Lewis, J. Pathol., 2002, 196, 254-265.

4 C. Gomezroca and J. P. Delord, Curr. Opin. Oncol., 2014, 26, 357-362.

5 K. Yang, S. Zhang, G. Zhang, X. Sun, S. T. Lee and Z. Liu, Nano Lett., 2010, 10, 3318-3323.

6 J. T. Robinson, S. M. Tabakman, Y. Liang, H. Wang, H. S. Casalongue, D. Vinh and H. Dai, J. Am. Chem. Soc., 2011, 133, 6825-6831.

7 H. C. Huang, Y. Yang, A. Nanda, P. Koria and K. Rege, Nanomedicine, 2016, 6, 459-473.

8 L. Zhang, Y. Chen, Z. Li, L. Li, P. Saint-Cricq, C. Li, J. Lin, C. Wang, Z. Su and J. I. Zink, Angew. Chem., Int. Ed., 2016, 136, 697-711.

9 T. J. Dougherty and S. L. Marcus, Eur. J. Cancer, 1992, 28, 1734-1742.

10 C. J. Gomer, Methods Mol. Biol., 2010, 635, 35-38.

11 A. P. Castano, P. Mroz and M. R. Hamblin, Nat. Rev. Cancer, 2006, 6, 535-545.

12 S. G. Bown, Photonics Lasers Med., 2016, 5, 91-100.

13 R. Xing, K. Liu, T. Jiao, N. Zhang, K. Ma, R. Zhang, Q. Zou, G. Ma and X. Yan, Adv. Mater., 2016, 28, 3669-3676.

14 K. Furukawa and H. Kato, Nippon Rinsho, 2002, 60, 332-338. 15 M. Castelli, J. Reiners and D. Kessel, Biomedical Optics, 2003, pp. 10-16.

16 X. Wang, J. Hu, P. Wang, S. Zhang, Y. Liu, W. Xiong and Q. Liu, Theranostics, 2015, 5, 772-786.

17 C. F. V. Nostrum, Adv. Drug Delivery Rev., 2004, 56, 9-16.

18 C. Huang, H. Bai, C. Li and G. Shi, Chem. Commun., 2011, 47, 4962-4964.

19 H. Bai, C. Li, X. Wang and G. Shi, Chem. Commun., 2010, 46, 2376-2378.

20 J. Kim, L. J. Cote, F. Kim, W. Yuan, K. R. Shull and J. Huang, J. Am. Chem. Soc., 2010, 132, 8180-8186.
21 C. Zhang, L. Ren, X. Wang and T. Liu, J. Phys. Chem. C, 2010, 114, 11435-11440.

22 S. Shi, C. Feng, E. B. Ehlerding and W. Cai, Bioconjugate Chem., 2014, 25, 1609-1619.

23 C. Xu, C. Zhao, L. Meng, W. Li, J. Ren and X. Qu, Small, 2014, 10, 1841-1847.

24 A. A. Balandin, Nat. Mater., 2011, 10, 569-581.

25 S. Li, Y. Shen, A. Xie, X. Yu, L. Qiu, L. Zhang and Q. Zhang, Green Chem., 2007, 9, 852.

26 J. L. Gardeatorresdey, E. Gomez, J. R. Peraltavidea, J. G. Parsons, H. Troiani and M. Joseyacaman, Langmuir, 2003, 19, 1357-1361.

27 S. S. Shankar, A. Rai, A. Ahmad and M. Sastry, Chem. Mater., 2008, 17, 566-572.

28 G. Chang, Y. Wang, B. Gong, Y. Xiao, Y. Chen, S. Wang, S. Li, F. Huang, Y. Shen and A. Xie, ACS Appl. Mater. Interfaces, 2015, 7, 11246-11256.

29 V. L. A. G. Lima, E. A. Mélo, M. I. S. Maciel, F. G. Prazeres, R. S. Musser and D. E. S. Lima, Food Chem., 2005, 90, 565568.

30 W. T. Li, H. W. Tsao, Y. Y. Chen, S. W. Cheng and Y. C. Hsu, Photochem. Photobiol. Sci., 2007, 6, 1341-1348.

31 I. Gomaa, S. E. Ali, T. A. El-Tayeb and M. H. Abdel-kader, Photodiagn. Photodyn. Ther., 2012, 9, 362-368.

32 Y. Xu, Q. Wu, Y. Sun, H. Bai and G. Shi, ACS Nano, 2010, 4, 7358-7362.

33 B. Wang, P. Liu and R. Tang, BioEssays, 2010, 32, 698-708.

34 P. Behrens and E. Baeuerlein, Biomimetic and bioinspired chemistry, WILEY-VCH, 2007.

35 C. E. Hamm, R. Merkel, O. Springer, P. Jurkojc, C. Maier, K. Prechtel and V. Smetacek, Nature, 2003, 421, 841-843.

36 W. S. Hummers and R. E. Offeman, J. Am. Chem. Soc., 1958, 80, 1339.

37 Y. Wang, B. Zhang, L. Zhu, Y. Li, F. Huang, S. Li, Y. Shen and A. Xie, ACS Appl. Mater. Interfaces, 2014, 6, 15000-15006.

38 B. Adhikari, A. Biswas and A. Banerjee, Langmuir, 2012, 28, 1460-1469.

39 N. Bouropoulos, S. Weiner and L. Addadi, Chemistry, 2001, 7, 1881-1888.

40 A. C. Ferrari and J. Robertson, Phys. Rev. B: Condens. Matter Mater. Phys., 2000, 61, 14095-14107.

41 Z. H. Ni, H. M. Wang, Y. Ma, J. Kasim, Y. H. Wu and Z. X. Shen, ACS Nano, 2008, 2, 1033-1039.

42 W. Hailiang, R. Joshua Tucker, L. Xiaolin and D. Hongjie, J. Am. Chem. Soc., 2009, 131, 9910-9911.

43 Y. Kashiwagi, K. Uchiyama, F. Kurashima, J. I. Anzai and T. Osa, Anal. Sci., 1999, 15, 907-909.

44 J. R. Esch, J. R. Friend, J. K. Kariuki, J. R. Esch, J. R. Friend and J. K. Kariuki, Int. J. Electrochem. Sci., 2010, 5, 1464-1474.

45 G. E. Campos and F. Martin, J. AOAC Int., 2016, DOI: 10.5740/ jaoacint.16-0232.

46 E. E. Pfündel, N. B. Ghozlen, S. Meyer and Z. G. Cerovic, Photosynth. Res., 2007, 93, 205-221.

47 K. C. Das and C. K. Das, Biochem. Biophys. Res. Commun., 2000, 277, 443-447.

48 A. Ahsan, S. M. Hiniker, M. A. Davis, T. S. Lawrence and M. K. Nyati, Cancer Res., 2009, 69, 5108-5114. 